\title{
Small-scale digitization goes big time Implementation of a scholarly digitization fund
}

0 ver the past year, the library at Simon Fraser University (SFU) has pioneered a small-scale scholarly digitization fund that has proven to be an effective and inexpensive tool for expanding our scholarly communication program into new disciplines and recruiting new content to our institutional repository (IR).

Our IR has been active since 2004, and yet it seems we are perpetually seeking interesting local collections to populate it and help us realize the critical mass that will showcase it as a viable publication platform for SFU authors. We've been actively seeking a way to move beyond article preprints and theses, and we realize we're not the only library in this predicament.

During Open Access Week 2009, Brian Owen (AUL, Systems and Processing) and I presented a routine workshop on tools for open access publishing for members of the campus community. After delivering a basic "Open Access 101" talk, we moved on to discuss the suite of publishing tools and hosting services offered by our library as part of our partnership in the Public Knowledge Project. ${ }^{1}$

One of the questions we received was particularly intriguing: "My research center has a number of old publications we'd like to digitize. Can you help us?" We were pleased to arrange a follow-up meeting, and within an hour of sitting down with representatives of the research group, had seen the shelf of publications in question, about 35 in number, mostly authored by SFU faculty.
It quickly emerged that the research center had valuable local content, not formally published, and no longer available electronically-in short, classic grey literature on the endangered list. It was clear that we all had the same idea for this project. It would involve scanning the documents in question, creating metadata, and depositing them in SFU's IR. The research center would provide the content and arrange scanning by the university's document solutions group. The library would commit to hosting, providing access in perpetuity, stable URLs, and discoverability via OAI standards.

For our part, we saw high-quality research of interest locally and beyond, and an interesting new collection for the IR. For the research center, such a project would save this research from potential obscurity.

However, the cost estimate for scanning these documents, although competitive, was several thousand dollars. Neither the research group nor the library had a clear source of funding for this-so for want of a few thousand dollars, we had no way to move forward immediately.

We discussed possible funding sources for the project, from both the library digitization arena and the discipline-specific field in question. In more than one case, it seemed that applying for the $\$ 3,000$ or

Gwen Bird is associate university librarian, collections services at Simon Fraser University, e-mail: gbird@sfu.ca

Contact Mike Furlough — series editor, assistant dean for scholarly communications, and codirector of the Office of Digital Scholarly Publishing at Penn State Universitywith article ideas, e-mail: mfurlough@psu.edu

(c) 2011 Gwen Bird 
so would cost more in our time than we'd receive if successful.

Concurrently, librarians held a series of meetings with a small number of faculty to get ideas for redeveloping our institutional repository. ${ }^{2}$ While planning to migrate our IR from DSpace to Drupal, we sought input from faculty members who had deposited significant collections in the IR and provided feedback, or asked for IR services beyond what we were currently able to deliver. We were also conscious that the literature on IRs suggests supporting "works that straddle the analog-digital divide." 3

A faculty member from the English department was one of several who suggested that focusing only on born-digital material was limiting our horizons. She recommended we consider recruiting vulnerable older works that were not now widely accessible, but which often represented years of work, such as biobibliographies and recordings of dramatic performances or readings.

A channel to digitize such material would assist scholars whose work wasn't in digital form. We would be offering an enticement, and in exchange they'd be much more likely to deposit the digital version in the IR.

This idea fit well with the common recommendation to conceive the IR as a service rather than a graveyard for documents.

The following week we received two more inquiries from other departments in the Faculty of Arts-a group that had been more challenging for us to reach with our scholarly communication program. One had seen the digitized newspaper collections we created as part of the Multicultural Canada Project, ${ }^{4}$ and inquired if we would digitize a historical community newspaper needed for a department research study. Another academic department had sets of papers associated with an endowed chair, going back 25 years, and not available electronically.

\section{The fund is born}

We brought the idea of a fund for small, campus-based digitization projects to our library's administrative group, and were tasked with drafting terms of reference for such a fund, including the goals, criteria, maximum funding per project, and the like. The draft terms were discussed by the administrative group, the liaison librarian team, the project manager for the IR, our special collections librarian, and the systems librarians involved in our previous digitization projects.

Ultimately we received approval for $\$ 50,000$ to run a pilot project, ${ }^{5}$ funded from unrestricted endowment funds "to expose SFU research and scholarship to the University and broader community, leading to greater visibility and knowledge transfer of SFU scholarship and research output." The fund's goals were set to align with both the university's strategic research plan, and the library's open access strategy. ${ }^{6}$

The criteria for inclusion stipulated that works had to:

- be authored by SFU-affiliated faculty, staff and students, or be from the SFU Library's collections, especially special collections,

- be scholarly in nature, or related to the teaching, learning, or research mission of SFU, and

- be "publication ready," as the library would not provide editing and proofreading services.

Further, the terms stated that the author or proposer must be willing and able to grant SFU the right to preserve and provide open access to the work, and explicitly stated that the fund would not be used to seek or pay for required copyright permissions. The maximum amount awarded to a single project would be $\$ 5,000$, and proposals with matching contributions-either cash, grant-funded or in-kind-would be given preference.

This was not our first effort to digitize 
a body of in-house content to deposit in the IR. Like many other libraries, we digitized our theses and dissertations. Because the university was founded in 1965 , it was possible for the library to go back to the beginning to digitize all 8,000 theses quite readily in our full-service library digitization center. The Scholarly Digitization Fund was different because the collections would be identified, and in most cases provided, by members of the campus community rather than the library. It was a pilot project, and a leap of faith, to see if others at SFU beyond the library were interested in digitization as a way to extend access to their work.

We spread the word of the new Scholarly Digitization Fund through our usual promotion channels: on the library's Web site, to academic departments via our liaison librarian network, on our scholarly communication blog, and via Twitter. At our request, the Office of Research Services sent the announcement out to SFU grant holders and included it on their Web site listing funding opportunities at the university.

As with other scholarly communication activities, we made efforts to integrate the fund into the university's research infrastructure beyond the library. Reporting to the vice president for research helps the library in these efforts, as does the solid reputation of our liaison librarians who ably form the frontline for scholarly communication initiatives with SFU faculty.

Applications and inquiries began coming in within a couple of weeks. The application from the original research center arrived within a month, was funded in full, and is currently in production.

\section{One year later}

Not quite one year in, the fund has exceeded our expectations. After five months we had approved nine applications and approved more than $\$ 31,000$ in projects. Recognizing that we needed to halt the rollercoaster at this point to revisit policies, we declared the first year of funding closed, and paused to regroup.

We had been using a process of rolling acceptance for the pilot year and were finding the consultation involved in the approval process quite time consuming. In light of these observations, the recommendations for sustainability that went forward, and were subsequently approved, are not surprising. We recommended that:

- the fund be regularized and form a part of our ongoing scholarly communication program,

- an annual deadline be established for receiving applications, and a call for proposals be issued several months before that deadline each year,

- a committee be created to consider all submitted applications, composed of the IR manager, a systems librarian, a liaison librarian, the supervisor of the library's digitization center, and the university librarian,

- applicants be required to sign the IR license at the time they receive news of a successful submission, and

- a submission form with checklist and information package be prepared, including a full description of the process and a metadata template.

The few proposals that were not funded were also instructive. One was rejected because it was far too large in scope, proposing to digitize an older body of work to add to an existing online departmental archive of student works. Another hoped to digitize the tables of contents of a local journal as a form of online indexing.

Since SFU library works closely with the Public Knowledge Project and the Synergies project ${ }^{7}$ to put the full-text of journals online, we instead referred this applicant toward those services with the view to digitizing and hosting the fulltext online. In a number of other cases library staff met with potential applicants to explore project ideas, and we suspect 
that future applications may emerge from these expressions of interest.

\section{Going forward}

The runaway success of this fund in its pilot phase took the library by surprise, and pleased us for a number of reasons. The library is home to a robust digitization center that has been built, at least in part, by external grant-funded projects. The Scholarly Digitization Fund has helped us to offer this resource to members of our own campus community.

The timing of such grant-funded projects is often out of our control, and has resulted in steep peaks and valleys in the need for temporary assistance in our digitization center. We are now able to use the projects funded in-house to even out the demand for such assistance, and offer stable part-time employment to local students.

IR commentator Mary Westell is one of the authors who has noted that the integration of the IR with a library digitization center as a critical success factor for IRs. ${ }^{8}$

This fund differs from other existing digitization funds we are aware of by virtue of its small scale, and local campus focus. It has also allowed us to hear directly from faculty members on campus about which material in our own special collections is the highest priority for digitization. Of the first nine funded projects, three were working with materials from our special collections, and not necessarily ones the library might have considered first as priorities for digitization.

The funded projects include scanning of text on paper, visual images, and sound files. Spanning academic departments in the Faculty of the Environment, and Arts and Social Science, research centers and one student group on campus, as well as library special collections, this fund has given our scholarly communication program reach into areas where previous initiatives had not.

For example, use of our central Open Access Fund has been highly concentrated in disciplines such as Health and Life Sciences, where many high-quality peer-reviewed OA journals using article processing charges have emerged. We had been seeking creative ways beyond journal hosting to offer scholarly communication services that appeal to scholars in the arts, humanities, and social sciences.

Appreciation from fund recipients has been effusive. Among other things, they have pointed out that the "digitization of works is hard to fund with research grants because the digitization work is not in itself 'research'. Therefore, by funding [this] project the library is making a valuable contribution to this understudied topic."

Another commented, "I am amazed at the potential of this thing in terms of the ability to make the story and research of [our department] known" to the wider audience it deserves.

In creating the Scholarly Digitization Fund, the SFU library posed a question to members of our campus community. We have been very pleased that the community has responded with such a resounding "yes."

\section{Notes}

1. More information about the Public Knowledge Project may be found at pkp. sfu.ca.

2. See ir.lib.sfu.ca for more information about SFU's information repository.

3. Dorothea Salo, "Innkeeper at the roach motel," Library Trends 57(Fall 2008): 98-123.

4. The Multicultural Canada Project may be accessed at www.multiculturalcanada. $\mathrm{ca} /$.

5. Information about SFU's Scholarly Digitization Fund may be found at www.lib. sfu.ca/collections/digitization-fund.

6. "Removing barriers: Open Access strategy at the SFU Library," www.lib.sfu.ca/filenewest/8537/OA\%20Support\%20Final.pdf.

7. Synergies, www.synergiescanada.org.

8. Mary Westell, "Institutional repositories: Proposed indicators of success," Library Hi Tech (2006): 211-26. n 